\title{
Long-Term Body Weight Maintenance among StrongWomen-Healthy Hearts Program Participants
}

\author{
Rebecca A. Seguin, ${ }^{1}$ Sara C. Folta, ${ }^{2}$ Miriam E. Nelson, ${ }^{3}$ Karla L. Hanson, ${ }^{4}$ \\ and Andrea Z. LaCroix ${ }^{5}$ \\ ${ }^{1}$ College of Human Ecology, Division of Nutritional Sciences, Cornell University, 412 Savage Hall, Ithaca, NY 14853, USA \\ ${ }^{2}$ Friedman School of Nutrition Science and Policy, Tufts University, 150 Harrison Avenue, Boston, MA 02111, USA \\ ${ }^{3}$ Sustainability Institute, University of New Hampshire, 107 Nesmith Hall, Durham, NH 03824, USA \\ ${ }^{4}$ College of Human Ecology, Division of Nutritional Sciences, Cornell University, 231 Savage Hall, Ithaca, NY 14853, USA \\ ${ }^{5}$ Family Medicine and Public Health, University of California, San Diego, 9500 Gilman Drive No. 0725, La Jolla, CA 92093, USA
}

Correspondence should be addressed to Rebecca A. Seguin; rs946@cornell.edu

Received 15 December 2016; Accepted 12 February 2017; Published 2 March 2017

Academic Editor: Ike S. Okosun

Copyright ( 92017 Rebecca A. Seguin et al. This is an open access article distributed under the Creative Commons Attribution License, which permits unrestricted use, distribution, and reproduction in any medium, provided the original work is properly cited.

\begin{abstract}
Background. The repeated loss and regain of body weight, referred to as weight cycling, may be associated with negative health complications. Given today's obesity epidemic and related interventions to address obesity, it is increasingly important to understand contexts and factors associated with weight loss maintenance. This study examined BMI among individuals who had previously participated in a 12-week, evidence-based, nationally disseminated nutrition and physical activity program designed for overweight and obese middle-aged and older women. Methods. Data were collected using follow-up surveys. Complete height and weight data were available for baseline, 12-week program completion (post-program) and follow-up (approximately 3 years later) for 154 women (response rate $=27.5 \%$; BMI characteristics did not differ between responders and nonresponders). Results. Mean BMI decreased significantly from baseline to post-program $(-0.5, P<0.001)$ and post-program to follow-up $(-0.7, P<0.001)$. Seventyfive percent of survey respondents maintained or decreased BMI post-program to follow-up. Self-efficacy and social support for healthy eating behaviors (but not physical activity) were associated with BMI maintenance or additional weight loss. Conclusions. These findings support the durability of weight loss following participation in a relatively short-term intervention.
\end{abstract}

\section{Introduction}

There is evidence that even modest amounts of weight loss can have beneficial effects on the health of obese individuals [1] and results can be achieved using a range of approaches, including programs that have focused on aerobic exercise [2], yoga [3], nutrition [4], combined diet and exercise [5], and mobile or electronic weight loss interventions [6].

It is important to note, however, that weight cyclingthe repeated loss and regain of body weight-may be associated with health complications such as excess body weight, abdominal fat accumulation [7], type 2 diabetes [8], physical limitations [9], and negative impacts on immune function [10]. Arnold et al. [9] also reported a deleterious association of weight cycling with mortality. Some researchers examining methodological challenges in measuring the impact of weight cycling point to reverse causality in these analyses, while others maintain that while this may be true, weight cycling can be harmful for some populations [11]. Not surprisingly, those with a history of weight cycling are at risk for regaining weight [12]. However, a review of data on the prevalence of successful weight maintenance revealed that maintaining weight loss for at least 1 year is achievable by only approximately $20 \%$ of overweight individuals who lost $10 \%$ of their initial body weight [13].

Thus, it is important to understand the contexts in which weight loss is occurring among at-risk populations and to follow these individuals over time so that risk for weight loss regain can be addressed in intervention planning as well as future dissemination efforts [14]. Furthermore, the 
relationships between self-efficacy and social support and long-term maintenance of weight loss are poorly understood. This is due in part to a dearth of studies that examine longer-term outcomes [15]. In some studies, social support has been linked with greater effectiveness of interventions in promoting healthy eating, physical activity, and weight loss at 18 or more months $[12,15,16]$. However, in the Weight Loss Maintenance Trial [17] and in other studies [18], social support from family and friends appeared to hinder longterm maintenance of weight loss. Type of social support received may help explain these contradictory findings [18]. Associations between self-efficacy and long-term maintenance of weight loss have been somewhat more consistent [19-23].

This study was designed to examine the durability of body mass index (BMI; defined as weight in kilograms divided the square of height in meters) maintenance following participation in an evidence-based nationally disseminated program [the StrongWomen-Healthy Hearts Program (SWHH)] that targets cardiovascular disease risk reduction through dietary behavior change and regular aerobic exercise. The 12-week program demonstrated significant weight loss among overweight and obese women with a dose of hour-long twice weekly classes, in both the original community randomized trial (2007-2008) and the national dissemination (22 states) conducted between 2010 and 2013 [24]. Here we address the following research questions: (1) Among former participants in the SWHH program, how does BMI change from the time of program completion to follow-up (approximately three years later)? (2) What is the trajectory of change in BMI among women who maintained BMI versus those who increased BMI? and (3) Is self-efficacy and/or social support associated with follow-up BMI?

\section{Materials and Methods}

2.1. Data Collection, Participants, and Setting. From August 2013 to December 2013, 600 SWHH participants received invitations to participate in this study, the StrongWomen Follow-Up Study (SWFUS), in the form of an online or paper-based survey. A total of 165 participant responses were received (84 online and 81 on paper). Participants in this sample included women 40 years of age and older who lived independently, were sedentary, and had a BMI of 24 or higher at baseline $[24,25]$. The analytic sample for this study included a total of 154 women (of the 165 respondents) for whom complete body weight data (height and weight) were available at all three points in time: baseline, post-program, and followup (approximately three years after baseline). The study was approved by the Institutional Review Board at Cornell University. Written consent was obtained from each participant.

2.2. Constructs and Measures. At baseline, height in centimeters $(\mathrm{cm})$ was measured; weight was measured in kilograms at baseline and post-program. All measures were collected in triplicate using standard procedures [26] and those results have been previously published [24]. Follow-up height, in feet and inches, and body weight, in pounds, were self-reported by participants on the SWFUS survey. Height and weight were used to calculate BMI [27] for all points in time. For some analyses, post-program and follow-up BMI also were calculated as percentages of baseline BMI. Program BMI change was the difference between post-BMI and pre-BMI; follow-up BMI change was computed by follow-up BMI less post-program BMI. For some analyses, BMI changes also were calculated as percentages of baseline BMI. Baseline BMI is divided into three categories: overweight or at-risk of overweight (24.0-29.9), obese (30.0-34.9), and severely obese $(\geq 35.0)$. Also, a dichotomous variable was computed for respondents as "yes, long-term BMI maintenance" if BMI decreased or remained unchanged from post-program to follow-up or "no long-term BMI maintenance" if BMI increased from post-program to follow-up.

Social factors were self-reported in the follow-up survey. Self-efficacy was measured by 16 items about self-efficacy for healthy eating and 14 items about self-efficacy for physical activity, adapted from Sallis et al. (1988) [28]. Scales for both self-efficacy for healthy eating (alpha $=0.92)$ and self-efficacy for physical activity (alpha $=0.95$ ) ranged from 1 (not at all confident) to 5 (completely confident). Social support for healthy eating was measured by the validated Sallis Social Support Survey for Diet [29]. Four scales were created: family encouragement (alpha $=0.87)$, friend encouragement (alpha $=0.87)$, family discouragement (alpha $=0.82)$, and friend discouragement ( $\mathrm{alpha}=0.75)$, each of which ranges from 1 (never) to 5 (very often). Social support for physical activity was measured by the validated Sallis Social Support Survey for Exercise Behaviors [29]. Two scales were created: participation in physical activity among family (alpha $=0.88)$ and participation among friends (alpha $=0.93)$, each of which ranged from 1 (never) to 5 (very often). Baseline demographic data included age, race, marital status, education, and employment.

2.3. Statistical Analysis. Preliminary $t$-test and chi-square analyses were conducted to assess baseline demographic and anthropometric differences between $\mathrm{SWHH}$ respondents (with complete height and weight data for all three time points) and SWHH respondents without complete height and weight data for all three time points. The first analyses were conducted to assess change in BMI among SWHH Program participants, by comparing baseline BMI to post-program BMI and post-program BMI to follow-up BMI, using paired samples $t$-tests. The second analysis was conducted to test association between program BMI change and long-term maintenance of BMI (post-program to follow-up), using a chi-square test. The third analysis used one-way analysis of variance (ANOVA) to compare differences in program BMI change and follow-up BMI change among baseline weight status groups. In the final analyses, Pearson productmoment correlations and point-biserial correlations were run to determine the relationships among self-efficacy and social support for healthy eating and physical activity and "followup BMI change."

Self-reported height is generally overreported, and body weight underreported [30] by approximately 1.89 kilograms $(95 \% \mathrm{CI}=1.87,1.91)$ among midlife and older women [31]. To adjust for these biases, we conducted two sensitivity analyses. 
TABLE 1: Baseline characteristics and post-program BMI change by SWFUS response.

\begin{tabular}{|c|c|c|c|}
\hline Characteristics at baseline & $\begin{array}{c}\text { No follow-up response } \mathrm{a}^{\mathrm{a}}(n=446) \text {, } \\
\text { mean }( \pm \mathrm{SD}) \text {, or } \%\end{array}$ & $\begin{array}{c}\text { SWFUS respondents }^{\mathrm{b}}(n=154), \\
\text { mean }( \pm \mathrm{SD}) \text {, or } \%\end{array}$ & $P$ value \\
\hline Mean age $( \pm S D)$ & $60.1(10.0)$ & $58.9(8.4)$ & 0.19 \\
\hline Race/ethnicity, \% & & & 0.09 \\
\hline White, non-Hispanic & $92.6(0.3)$ & $88.1(0.3)$ & \\
\hline Education, \% & & & 0.81 \\
\hline High school or less & 25.4 & 23.8 & \\
\hline Some college & 35.5 & 37.3 & \\
\hline Bachelor's degree & 20.2 & 17.5 & \\
\hline Graduate training & 18.9 & 21.4 & \\
\hline Employed, yes, \% & 49.6 & 51.4 & 0.72 \\
\hline Household income level, \% & & & 0.56 \\
\hline$<\$ 50,000$ & 54.9 & 49.6 & \\
\hline$\$ 50,000-74,999$ & 22.8 & 22.1 & \\
\hline$\$ 75,000-100,000$ & 13.3 & 16.0 & \\
\hline$>\$ 100,000$ & 9.0 & 12.2 & \\
\hline Married, yes, \% & 67.7 & 77.7 & $0.03^{*}$ \\
\hline Mean BMI ( $\pm S D)$, baseline & $33.6(6.1)$ & $33.4(6.1)$ & 0.74 \\
\hline $\begin{array}{l}\text { Mean BMI change ( } \pm S D) \text {, baseline to } \\
\text { post-program }\end{array}$ & $-0.50(0.9)$ & $-0.50(0.9)$ & 0.99 \\
\hline
\end{tabular}

${ }^{\text {a }}$ Sample size varied from 397 to 446 due to missing data.

${ }^{\mathrm{b}}$ Sample size varied from 126 to 154 due to missing data.

Differences across follow-up response were tested using Chi-square analyses and $t$-tests. Boldface indicates statistical significance $\left({ }^{*} P<0.05\right)$.

BMI, body mass index; SWFUS, StrongWomen Follow-Up Study.

First, we subsequently added the upper limit of this confidence interval to each respondent's follow-up body weight and recalculated BMI. Second, we also recalculated followup BMI using measured height from baseline. Mean "selfreport adjusted" follow-up BMI, using these two methods, were compared to post-program BMI using a paired $t$-test, and results are provided in the text.

\section{Results}

3.1. Demographics. Baseline characteristics of follow-up survey SWHH respondents with complete height and weight data for all three time points $(n=154)$ and SWHH nonresponders $(n=446)$ were equivalent, except for the percentage married, which was higher among respondents than nonrespondents $(77.7 \%$ versus $67.7 \%$, resp., $P=0.03)$, Table 1. There was no difference between mean age at baseline among nonrespondents (mean $=60.1, \pm \mathrm{SD}=10.0$ ) and respondents $($ mean $=58.9, \pm \mathrm{SD}=8.4), P=0.19$. The majority of the respondents and nonrespondents were white $(P=0.09)$ and had evenly distributed educational attainment across the categories of "high school or less," "some college," "bachelor's degree," and "graduate training" $(P=0.81)$. There were no differences in the reported household income levels of respondents and nonrespondents, with both groups reporting household income levels less than $\$ 50,000(P=$ $0.56)$. Importantly, baseline BMI was equivalent among nonrespondents and respondents $(P=0.74)$, as was BMI change
TABLE 2: Mean BMI at baseline, post-program, and follow-up ( $n=$ 154).

\begin{tabular}{|c|c|c|c|}
\hline & $\begin{array}{c}\text { Baseline } \\
\text { Mean }( \pm \mathrm{SD})\end{array}$ & $\begin{array}{c}\text { Post-program } \\
\text { Mean }( \pm S D)\end{array}$ & $\begin{array}{c}\text { Follow-up }{ }^{\mathrm{a}} \\
\text { Mean }( \pm \mathrm{SD})\end{array}$ \\
\hline BMI & $33.4(6.1)$ & $32.9(6.0)^{* * *}$ & $31.6(5.8)^{* * *}$ \\
\hline$\%$ of baseline BMI & $100.0(0.0)$ & $98.5(2.7)^{* * *}$ & $94.8(7.8)^{* * *}$ \\
\hline
\end{tabular}

from baseline to post-program among nonrespondents and respondents $(P=0.99)$.

3.2. Change in BMI. The results in Table 2 show mean BMI at baseline, post-program, and follow-up among participants. Mean BMI decreased significantly from baseline to postprogram $(-0.5$ or $1.5 \%$ of baseline BMI, $P<0.001)$ and from post-program to follow-up $(-1.3$ or $3.7 \%$ of baseline BMI, $P<$ $0.001)$ which is approximately 3 kilograms. After adjusting follow-up body weight for potential self-report bias, followup BMI (mean $=32.2, \pm \mathrm{SD}=5.8$ ) was still significantly lower than measured post-program BMI $(-0.7, P<0.001)$. After recalculating follow-up BMI using measured rather than selfreported height, follow-up BMI $($ mean $=31.8 ; \pm \mathrm{SD}=5.7$ ) 
TABLE 3: Mean program and follow-up BMI change by weight status groups $(n=154)$.

\begin{tabular}{|c|c|c|c|}
\hline & \multicolumn{3}{|c|}{ Weight status } \\
\hline & Overweight $(a)(n=50)$ & Obese $(b)(n=53)$ & Very obese $(c)(n=51)$ \\
\hline & Mean $( \pm$ SD) & Mean $( \pm \mathrm{SD})$ & Mean $( \pm \mathrm{SD})$ \\
\hline Program BMI change & $-0.43(0.79)$ & $-0.43(0.89)$ & $-0.64(0.97)$ \\
\hline Program BMI change as $\%$ of baseline BMI & $-1.56(2.93)$ & $-1.35(2.74)$ & $-1.59(2.42)$ \\
\hline Follow-up BMI change & $-0.30(1.97)^{b, c}$ & $-1.51(2.27)^{a}$ & $-2.24(3.01)^{a * * *}$ \\
\hline Follow-up BMI change as \% of baseline BMI & $-1.07(7.24)^{b, c}$ & $-4.52(6.94)^{a}$ & $-5.55(7.47)^{a * *}$ \\
\hline
\end{tabular}

Note: $a, b$, and $c$ indicate which means are significantly different from each other via post hoc tests (Tukey).

Boldface indicates statistically significant $F$-test at ${ }^{* *} P<0.01$ and ${ }^{* * *} P<0.001$.

BMI, body mass index.

TABLE 4: Correlation between self-efficacy and social support for healthy eating and physical activity and BMI change.

\begin{tabular}{|c|c|c|}
\hline & $\begin{array}{l}\text { Follow-up BMI change } \\
\qquad(n=153)\end{array}$ & $\begin{array}{l}\text { Follow-up BMI change } \\
\text { as } \% \text { of baseline BMI }\end{array}$ \\
\hline \multicolumn{3}{|l|}{ Self-efficacy and social support } \\
\hline \multicolumn{3}{|l|}{ Healthy eating } \\
\hline Self-efficacy for healthy eating & $-0.17^{*}$ & $-0.18^{*}$ \\
\hline \multicolumn{3}{|l|}{ Social support for healthy eating } \\
\hline Family encourages & -0.05 & -0.04 \\
\hline Family discourages & -0.04 & -0.03 \\
\hline Friends encourage & $-0.20^{*}$ & $-0.19^{*}$ \\
\hline Friends discourage & -0.10 & -0.03 \\
\hline \multicolumn{3}{|l|}{ Physical activity } \\
\hline Self-efficacy for physical activity & -0.07 & -0.08 \\
\hline \multicolumn{3}{|l|}{ Social support for physical activity } \\
\hline Family participates & +0.05 & +0.04 \\
\hline Friends participate & +0.06 & +0.07 \\
\hline
\end{tabular}

Boldface indicates statistical significance $\left({ }^{*} P<0.05\right)$.

BMI, body mass index.

was also still significantly lower than post-program BMI $(-1.1$, $P<0.001)$.

There were no significant differences observed in BMI change during the program period among the three baseline weight status groups. However, a significant difference was found in follow-up BMI change among weight status groups; overweight participants lost less weight than did obese and very obese participants $(P<0.01)$, Table 3 .

Seventy-four percent of SWHH participants $(n=114)$ maintained their post-program BMI (or lost additional body weight) during the follow-up period, with a mean weight loss of -5.16 kilograms $( \pm S D=5.72)$ while $26 \%$ gained weight $(n=40)$, with a mean weight gain of +3.08 kilograms $( \pm \mathrm{SD}=$ 3.77) $(P<0.001)$; data not shown. These data also show that $72 \%$ of those who decreased their BMI during the program maintained it post-program, and similarly $79 \%$ of those who lost no body weight during the program also lost weight or maintained their body weight post-program, a difference that is not significant (chi-square $=0.43$; data not shown).
There were statistically significant correlations between self-efficacy for healthy eating and follow-up BMI change ( $r=-0.17, P=0.04)$ and between friends encouragement of healthy eating and follow-up BMI change $\left(r_{p b}=-0.20\right.$, $P=0.02$ ), Table 4 . There were no associations between selfefficacy and social support for physical activity and follow-up BMI change.

\section{Discussion}

This study aimed to understand BMI maintenance among former SWHH program participants approximately three years later as well as to examine relationships with BMI maintenance and social support and self-efficacy. Overall, SWHH participants maintained their weight loss and, in some cases, lost additional weight over the three years after the program ended. On average, participants further reduced their weight by more than three percent of baseline BMI, or about three kilograms. According to results from a national sample of 
adults who successfully maintained weight loss for at least one year, a little over half of the sample reported they had lost weight through formal programs and the rest lost weight on their own [32], but the data in this area are very limited.

On average, SWHH participants with higher baseline BMI (obese and very obese categories) had significantly more BMI reduction in the follow-up period than did participants with lower baseline BMI (overweight category), despite equivalent weight loss in the program period. This is possibly due to response bias. One prior review found that successful weight maintenance was associated with more initial weight loss [12], but these data suggest otherwise.

Self-efficacy for healthy eating was associated with successful long-term BMI maintenance, similar to other studies [33]. Social support for healthy eating was likewise associated with long-term BMI maintenance. Results of other studies that examine social support and weight loss maintenance are inconsistent, although there is some evidence that compliments and active participation may be helpful while verbal instruction and encouragement may be perceived negatively [18]. To help elucidate the role of social support in weight maintenance, future studies may use mixed methods in which type of support is examined and qualitative data are collected to determine how different types of support are perceived. Contrary to other studies [22,34], self-efficacy and social support for physical activity were unrelated to maintenance; this is potentially the result of differences in study populations, intervention strategies, and measurement of self-efficacy. Maintenance of physical activity and/or dietary behavior change is often not reported in weight maintenance studies, according to a systematic review of the evidence [35]. One review found that successful weight maintenance was associated with behaviors such as having a physically active lifestyle, regular meal rhythm, control of over-eating, and self-monitoring of behaviors [12].

There are some limitations of this study worth noting. Height and body weight at baseline, and body weight postprogram were measured, whereas follow-up data collection relied on self-reported height and weight. Relative to objective measures, self-reported height is generally overestimated and body weight is underestimated [30]. There is some evidence to suggest that reporting bias may have contributed to declines in BMI observed during the follow-up period. Higher baseline BMI was related to larger decreases in BMI during the follow-up period but was unrelated to BMI change during the program period. If larger decreases in BMI among individuals with higher body weight were due to the relatively larger amount of weight to lose, we would expect this relationship to hold true during both time periods. Neither of our two approaches to adjusting BMI for self-report bias influenced our findings or their statistical significance, suggesting that bias did not account for the entire observed difference. Additionally, these data only represent one followup time point; it will be important to collect additional data in the future to understand long-term maintenance and possible weight cycling. It is possible that SWHH follow-up study responders were more successful with weight maintenance than nonresponders. Nevertheless, even if responders maintained their weight more often than nonresponders, responder weight maintenance rates are similar to, or higher than, what other studies have reported [36].

\section{Conclusion}

These findings support the durability of weight loss following participation in a relatively short-term intervention. Self-efficacy for healthy eating and social support for healthy eating were related to successful BMI maintenance.

\section{Competing Interests}

The authors declare that they have no competing interests.

\section{References}

[1] D. J. Goldstein, "Beneficial health effects of modest weight loss," International Journal of Obesity, vol. 16, no. 6, pp. 397-415, 1992.

[2] J. E. Donnelly, J. J. Honas, B. K. Smith et al., "Aerobic exercise alone results in clinically significant weight loss for men and women: midwest exercise trial 2," Obesity, vol. 21, no. 3, pp. E219-E228, 2013.

[3] J. Rioux and C. Ritenbaugh, "Narrative review of yoga intervention clinical trials including weight-related outcomes," Alternative Therapies in Health and Medicine, vol. 19, no. 3, pp. 32-46, 2013.

[4] P. J. Taylor, G. S. Kolt, C. Vandelanotte et al., "A review of the nature and effectiveness of nutrition interventions in adult males-a guide for intervention strategies," International Journal of Behavioral Nutrition and Physical Activity, vol. 10, article no. 13, 2013.

[5] M. Lara and H. Amigo, "What kind of intervention has the best results to reduce the weight in overweighted or obese adults?" Archivos Latinoamericanos de Nutricion, vol. 61, no. 1, pp. 45-54, 2011.

[6] L. N. Lyzwinski, "A Systematic review and meta-analysis of mobile devices and weight loss with an intervention content analysis," Journal of Personalized Medicine, vol. 4, no. 3, pp. 311385, 2014.

[7] E. Cereda, A. E. Malavazos, R. Caccialanza, M. Rondanelli, G. Fatati, and M. Barichella, "Weight cycling is associated with body weight excess and abdominal fat accumulation: a crosssectional study," Clinical Nutrition, vol. 30, no. 6, pp. 718-723, 2011.

[8] M. Kataja-Tuomola, J. Sundell, S. Männistö et al., "Short-term weight change and fluctuation as risk factors for type 2 diabetes in Finnish male smokers," European Journal of Epidemiology, vol. 25, no. 5, pp. 333-339, 2010.

[9] A. M. Arnold, A. B. Newman, M. Cushman, J. Ding, and S. Kritchevsky, "Body weight dynamics and their association with physical function and mortality in older adults: the Cardiovascular Health Study," Journals of Gerontology, Series A: Biological Sciences and Medical Sciences, vol. 65, no. 1, pp. 63-70, 2010.

[10] E. D. Shade, C. M. Ulrich, M. H. Wener et al., "Frequent intentional weight loss is associated with lower natural killer cell cytotoxicity in postmenopausal women: possible long-term immune effects," Journal of the American Dietetic Association, vol. 104, no. 6, pp. 903-912, 2004.

[11] A. Bosy-Westphal and M. J. Müller, "Measuring the impact of weight cycling on body composition: a methodological 
challenge," Current Opinion in Clinical Nutrition and Metabolic Care, vol. 17, no. 5, pp. 396-400, 2014.

[12] K. Elfhag and S. Rössner, "Who succeeds in maintaining weight loss? A conceptual review of factors associated with weight loss maintenance and weight regain," Obesity Reviews, vol. 6, no. 1, pp. 67-85, 2005.

[13] R. R. Wing and S. Phelan, "Long-term weight loss maintenance," The American Journal of Clinical Nutrition, vol. 82, no. 1, pp. 222S-225S, 2005.

[14] S. C. Folta, R. A. Seguin, K. K. H. Chui et al., "National dissemination of strongwomen-healthy hearts: a communitybased program to reduce risk of cardiovascular disease among midlife and older women," American Journal of Public Health, vol. 105, no. 12, pp. 2578-2585, 2015.

[15] C. J. Greaves, K. E. Sheppard, C. Abraham et al., "Systematic review of reviews of intervention components associated with increased effectiveness in dietary and physical activity interventions," BMC Public Health, vol. 11, article 119, 2011.

[16] M. L. Wang, L. Pbert, and S. C. Lemon, "Influence of family, friend and coworker social support and social undermining on weight gain prevention among adults," Obesity, vol. 22, no. 9, pp. 1973-1980, 2014.

[17] L. P. Svetkey, J. D. Ard, V. J. Stevens et al., "Predictors of longterm weight loss in adults with modest initial weight loss, by sex and race," Obesity, vol. 20, no. 9, pp. 1820-1828, 2012.

[18] E. Karfopoulou, C. A. Anastasiou, E. Avgeraki, M. H. Kosmidis, and M. Yannakoulia, "The role of social support in weight loss maintenance: results from the MedWeight study, Journal of Behavioral Medicine, vol. 39, no. 3, pp. 511-518, 2016.

[19] E. S. Anderson-Bill, R. A. Winett, J. R. Wojcik, and S. G. Winett, "Web-based guide to health: relationship of theoretical variables to change in physical activity, nutrition and weight at 16-months," Journal of Medical Internet Research, vol. 13, no. 1, article e27, 2011.

[20] S. M. Byrne, "Psychological aspects of weight maintenance and relapse in obesity," Journal of Psychosomatic Research, vol. 53, no. 5, pp. 1029-1036, 2002.

[21] A. N. Szabo-Reed, J. Lee, L. Ptomey et al., "Longitudinal weight loss patterns and their behavioral and demographic associations," Annals of Behavioral Medicine, vol. 50, no. 1, pp. 147-156, 2016.

[22] P. J. Teixeira, M. N. Silva, S. R. Coutinho et al., "Mediators of weight loss and weight loss maintenance in middle-aged women," Obesity, vol. 18, no. 4, pp. 725-735, 2010.

[23] B. C. Wingo, R. A. Desmond, P. Brantley et al., "Self-efficacy as a predictor of weight change and behavior change in the PREMIER trial," Journal of Nutrition Education and Behavior, vol. 45, no. 4, pp. 314-321, 2013.

[24] S. C. Folta, A. H. Lichtenstein, R. A. Seguin, J. P. Goldberg, J. F. Kuder, and M. E. Nelson, "The strongwomen-healthy hearts program: reducing cardiovascular disease risk factors in rural sedentary, overweight, and obese midlife and older women," American Journal of Public Health, vol. 99, no. 7, pp. 1271-1277, 2009.

[25] S. C. Folta, A. H. Lichtenstein, R. A. Seguin et al., "The StrongWomen-Healthy Hearts program in Pennsylvania: REAIM analysis," Translational Behavioral Medicine, vol. 5, no. 1, pp. 94-102, 2015.

[26] T. Lohman, Advances in Body Composition Assessment, Current Issues in Exercise Science Series, Human Kinetics Publishers, Champaign, Ill, USA, 1992.
[27] World Health Organization, Physical Status: The Use and Interpretation of Anthropometry, WHO Technical Report Series no. 854, World Health Organization, 1995.

[28] J. F. Sallis, R. B. Pinski, R. M. Grossman, T. L. Patterson, and P. R. Nader, "The development of self-efficacy scales for healthrelated diet and exercise behaviors," Health Education Research, vol. 3, no. 3, pp. 283-292, 1988.

[29] J. F. Sallis, R. M. Grossman, R. B. Pinski, T. L. Patterson, and P. R. Nader, "The development of scales to measure social support for diet and exercise behaviors," Preventive Medicine, vol. 16, no. 6, pp. 825-836, 1987.

[30] S. C. Gorber, M. Tremblay, D. Moher, and B. Gorber, "A comparison of direct vs. self-report measures for assessing height, weight and body mass index: a systematic review," Obesity Reviews, vol. 8, no. 4, pp. 307-326, 2007.

[31] A. A. Wanigatunga, S. S. Sourdet, M. J. LaMonte et al., "Physical impairment and body weight history in postmenopausal women: the Women's Health Initiative," Public Health Nutrition, vol. 19, no. 17, 2016.

[32] M. L. Klem, R. R. Wing, M. T. McGuire, H. M. Seagle, and J. O. Hill, "A descriptive study of individuals successful at longterm maintenance of substantial weight loss," American Journal of Clinical Nutrition, vol. 66, no. 2, pp. 239-246, 1997.

[33] M. T. Warziski, S. M. Sereika, M. A. Styn, E. Music, and L. E. Burke, "Changes in self-efficacy and dietary adherence: the impact on weight loss in the PREFER study," Journal of Behavioral Medicine, vol. 31, no. 1, pp. 81-92, 2008.

[34] P. J. Teixeira, S. B. Going, L. B. Houtkooper et al., "Exercise motivation, eating, and body image variables as perdictors of weight control," Medicine and Science in Sports and Exercise, vol. 38, no. 1, pp. 179-188, 2006.

[35] B. Fjeldsoe, M. Neuhaus, E. Winkler, and E. Eakin, "Systematic review of maintenance of behavior change following physical activity and dietary interventions," Health Psychology, vol. 30, no. 1, pp. 99-109, 2011.

[36] J. C. M. Barte, N. C. W. ter Bogt, R. P. Bogers et al., "Maintenance of weight loss after lifestyle interventions for overweight and obesity, a systematic review," Obesity Reviews, vol. 11, no. 12, pp. 899-906, 2010. 


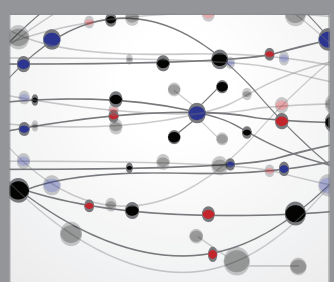

The Scientific World Journal
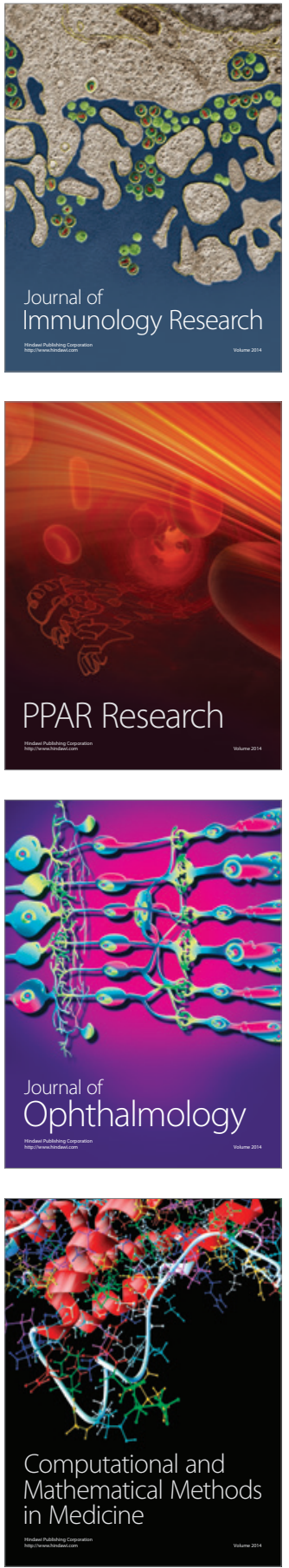

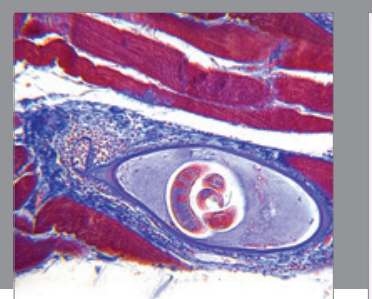

Gastroenterology Research and Practice
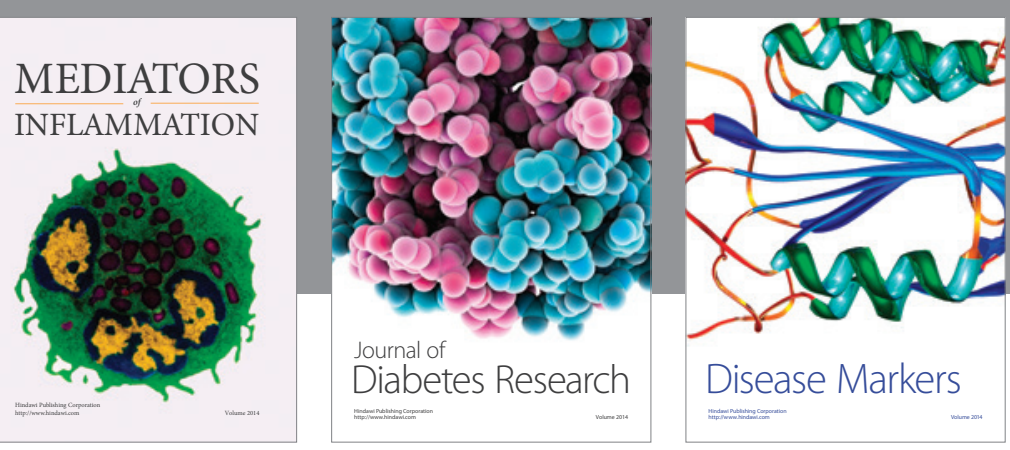

Disease Markers

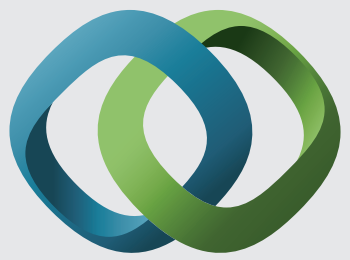

\section{Hindawi}

Submit your manuscripts at

https://www.hindawi.com
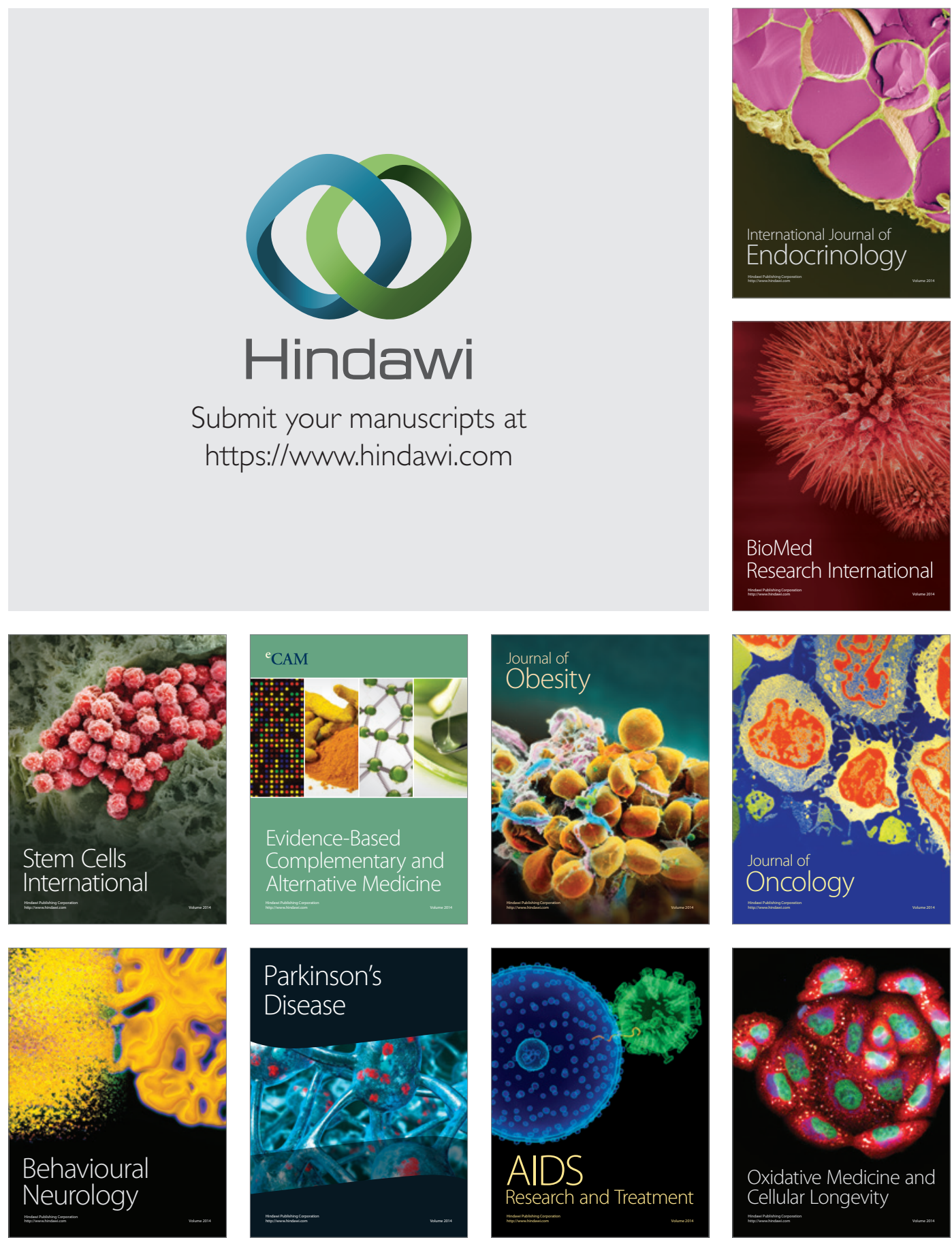